\title{
The association between dispositional mindfulness and empathy among undergraduate nursing students: A multicenter cross-sectional study
}

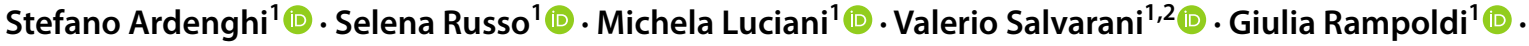

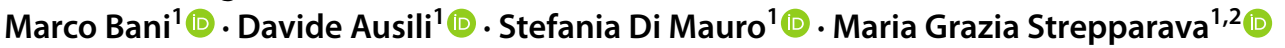

Accepted: 27 January 2022

(c) The Author(s) 2022

\begin{abstract}
The aim of this study was to explore the role of gender, age, and academic year in shaping dispositional mindfulness (DM) and the association between DM facets and empathy dimensions in a sample of undergraduate nursing students. In a multicenter cross-sectional study design, the Five Facet Mindfulness Questionnaire (FFMQ), the Interpersonal Reactivity Index (IRI), and socio-demographic questions were administrated to a convenience sample of Italian nursing students. 622 nursing students $(82.2 \%$ female) participated in the study (response rate $=86.15 \%)$. Females had higher levels of Acting with Awareness $(p<.001, d=.54)$ and lower levels of Non-reacting $(p<.001, d=.52)$ facets of DM than males. Older students displayed higher scores on the Observing $(r=.112, p=.005)$ and on the Non-reacting $(r=.187, p<.001)$ FFMQ subscales than younger ones. No statistically significant differences in DM levels between the three academic years were found $(p s>.202)$. After controlling for socio-demographic factors, DM facets were generally positively related to Perspective Taking ( $\beta$ s from .131 to $.208, p s$ < .007) and Empathic Concern $(\beta \mathrm{s}$ from -.156 to $.189, p \mathrm{~s}<.001)$, whereas negatively related to Personal Distress ( $\beta$ s from -.141 to $-.261, p \mathrm{~s}<.001$ ). Nursing students with higher levels of DM were more able to consider others' cognitive perspective and to feel compassion, and were less emotionally distressed when facing tense interpersonal situations. Tailored mindfulness interventions might be useful to foster functional empathy within nursing undergraduate programs.
\end{abstract}

Keywords Dispositional mindfulness $\cdot$ Empathy $\cdot$ Nursing students $\cdot$ Nursing education

\section{Introduction}

Empathy is a crucial aspect of a functional and effective patient-nurse relationship with nurses' good empathetic capacities being linked to greater well-being and satisfaction (Richardson et al., 2012), greater treatment compliance and better health outcomes in patients (Derksen et al., 2017). In addition, empathy is associated with higher professional satisfaction (Ozcan et al., 2010) and with lower levels of burnout amongst nurses and nursing students (WilczekRużyczka, 2011). Lack of empathy may undermine care

Maria Grazia Strepparava

mariagrazia.strepparava@unimib.it

1 Department of Medicine and Surgery, University of Milano - Bicocca, Via Cadore 48, 20900 Monza, MB, Italy

2 Clinical Psychological Unit, Mental Health Department, San Gerardo Hospital, Via Pergolesi 33, Monza 20900, MB, Italy processes and the nurse-patient relationship as suggested by a review of cases presented to a nurses' disciplinary tribunal where the majority of complaints against nurses resulted from lack of empathy and indifference towards patients and their families (Doyle et al., 2014). Empathy is generally conceptualized as a multidimensional construct comprising cognitive and emotional aspects (Davis, 1980). Although research on empathy hints a possible gender difference due to adherence to gender-role stereotypes (Ardenghi etal., 2021a; Luciani et al., 2020), the development of empathic skills is strongly dictated by the educational environment (Brunero et al., 2010).

Nurses and nursing students are faced with several stressors such as time constraints, heavy workload, contact with serious ill or dying patients, patients' and families' emotional surge, and overidentification with psychomotor tasks (Baillie, 1996). Academic education and early training experiences have the potential to foster as well as to impair empathy (Brunero et al., 2010). Hence, there is a 
growing interest in detecting the dispositional variables, such as attachment styles (Ardenghi et al., 2020a), personal values (Ardenghi et al., 2021b), emotion regulation (Ardenghi et al., 2021d; Salvarani et al., 2020), patientcentered orientation (Ardenghi et al., 2020b), self-efficacy and personality traits (Barbaranelli et al., 2021) to nurture healthcare students and professionals' empathic competencies and decrease emotional distress. In this pursuit, research has detected several skills and qualities linked to empathy which also characterized dispositional mindfulness (DM) including receptivity, non-judgmental attitudes, active listening, the ability to free the mind from distractions, and to remain in the "here and now" (Ardenghi et al., 2021a). Moreover, mindfulness exercises seem to produce changes in the same brain areas that have been linked to empathy, namely the prefrontal cortex, the anterior cingulate cortex and the anterior insula (Shamay-Tsoory, 2011).

Mindfulness has been defined as the awareness that results from a purposeful and non-judgmental attention in the present moment, while DM has been outlined as a personality trait linked to the ability of focusing and maintaining attention to the present moment with an open and non-judgmental outlook (Kabat-Zinn, 2003). DM has been conceptualized as a multidimensional and multi-faceted construct housing five dimensions: observing which is the ability to perceive and recognize internal or external stimuli; describing, that is, labelling with words the living experience: acting with awareness, to focus attention on one's current activity; non-judging of inner experience, which means to experience thoughts and feelings without judging or criticizing them; and non-reacting to inner experience, refers to active detachment from thoughts and emotions as mean to accept their existence and choose not to react to them (Baer et al., 2006). The basic attentional processes involved in DM (observing, describing and acting with awareness) could be key elements in developing and fostering empathy. To be able to consciously and purposively stay in the present moment and to observe and describe our own emotions would also enable us to better decipher others' suffering and their desires on how to alleviate it (Jinpa et al., 2009). Further, being able to approach our own emotions in a non-judgmental and non-reacting fashion, can function as kindling to develop empathy since these capacities would allow us to distance ourselves from strong emotional reactions, making more likely to understand, to take care of and to respond properly to the other people's feelings (Wallmark et al., 2013).

Several studies have explored the association between DM and empathy dimensions in the general population. Evidence on DM and empathy relationship is not clear cut and results are mixed and weak. Direction and intensity of results may greatly vary according to the instruments used to measure the constructs (Fuochi \& Voci, 2020). Nevertheless, it has emerged a positive association between empathy and both the tendency to notice sensations and stimuli in the present moment and the ability to label one's own emotion (Beitel et al., 2005; Berry et al., 2018). Furthermore, emotional distress has been found to negatively correlate with the DM facets of acting with awareness, acceptance, and describing, but unrelated to observing (Dekeyser et al., 2008). As for gender, greater DM has been found to be associated with being males and older (Alispahi \& Hasanbegovi-Anic, 2017). In healthcare providers greater DM has been found to be associated with lower work-related stress (Salvarani et al., 2019) and higher other-oriented behaviors (Hegel et al., 2021), greater resilience (Chamberlain et al., 2016), greater psychological wellbeing and greater self-compassion (Voci et al., 2016), adopting prosocial behaviors (Donald et al., 2019), lower levels of stress and burnout (Yang et al., 2017). An increase in DM has been linked to specific mindfulness training experiences amongst students (de Bruin et al., 2015) and in the general population (Duncan \& Bardacke, 2010).

Despite a few studies have highlighted the effect of mindfulness-based trainings on well-being and empathy in healthcare students (Beddoe \& Murphy, 2004) there are none assessing the association between DM and empathy in nursing students. A pilot study exploring the effects of a mindfulness-based stress reduction course has demonstrated an increase of empathy in nursing students (Beddoe \& Murphy, 2004) supporting the connection between empathy and DM. However, a deeper knowledge of DM facets in this population and their relationship with empathy could help educators to tailor mindfulness-based trainings to enhance empathy and decrease distress in nursing students. According to these gaps, the present cross-sectional study aimed to:

1. Describe DM facets in nursing students, exploring the role of gender, age, and academic year. We expected higher levels of DM in male and in older students for some or all DM facets but no difference between senior and junior students. We did not expect any differences in DM between academic years as no formal training on mindfulness was offered to students in the context of the study.

2. Explore the association between DM facets of empathy dimensions. We expected DM being positively associated with the ability to feel compassion for others and to adopt their perspective, and negatively associated with personal distress from emotional contagion.

\section{Methods}

\section{Design, Participants and Procedure}

This is a multicenter cross-sectional study involving five teaching hospitals linked to one University in northern 
Italy. University and hospitals did not provide any courses or programs on meditation and/or mindfulness trainings. Participants were a convenience sample of undergraduate nursing students at different academic years. Eligibility criteria for participants were: a) being enrolled in an undergraduate nursing program; b) being 18 years old or older; c) being proficient in Italian language; d) being able to provide informed consent. No exclusion criteria were applied. A paper-and-pencil questionnaire was administered to participants and took about $30 \mathrm{~min}$. Participants were approached after a scheduled class and invited to take part to the study. They were informed that participation was voluntary and their responses would be confidential and anonymous, and that they could withdraw at any point. All participants provided a written consent form. Ethical approval was received by the Institutional Review Boards of the study centers.

\section{Measures}

The study battery included socio-demographic and academic information such as gender, age, academic year, nationality, and parental status. Furthermore, it included validated questionnaire to measure constructs of interest.

DM was measured with the Italian version of the Five Facet Mindfulness Questionnaire (FFMQ) (Baer et al., 2006; Giovannini et al., 2014). The FFMQ is a 39-item self-report instrument assessing five components of DM: Observing, that is, the ability to focus on inner feelings and reactions to stimuli; Describing, which is the ability to verbalize one's thoughts and feelings; Acting with Awareness or the tendency to make conscious and deliberate actions as opposed to automatically react with no reflection; Nonjudging of inner experience, namely, the competence to be not judgmental towards one's own inner state, thoughts and emotions, and to accept them; Non-reacting to inner experience which is the ability to process disturbing stimuli without impulsive reactions. Respondents are asked to provide their accordance with each item on a 5-point Likerttype scale $(1=$ "never or very rarely true", $5=$ "very often or always true"). The Cronbach's alpha coefficients of the FFMQ English version (Baer et al., 2006) ranged from .75 to .91 , whereas those of the Italian validated version of the FFMQ (Giovannini et al., 2014) ranged from .75 to .91. In this study, the Cronbach's alpha coefficients for the five DM facets ranged between .71 and .88 , which are within the acceptable range.

Empathy was measured with the Italian version of the Interpersonal Reactivity Index (IRI) (Davis, 1980; Albiero et al., 2006), one of the most widely used scales to assess empathy in healthcare students according to Fragkos et al.'s meta-analysis (2019). The IRI is a four 7-item subscales measuring both cognitive and emotional dimensions of empathy: Perspective Taking assesses the spontaneous inclination to consider others' perspectives; Empathic Concern measures, feelings of warmth, compassion and concern for others; Personal Distress refers to emotional contagion and indicates the feelings of anxiety and discomfort when witnessing negative experiences of others; and Fantasy measures the tendency to imaginatively transpose oneself into fictional situations and characters. As the Fantasy subscale has been proven not to be relevant to patient care (Hojat et al., 2005), it was omitted in the current study. Each item is scored on a 5-point Likert scale ranging from 0 ("does not describe me well") to 4 ("describes me very well") with higher scores indicating higher levels of empathy. The Cronbach's alpha coefficients of the original IRI English version (Davis, 1980) ranged from .71 to .77, whereas those of the Italian validated version (Albiero et al., 2006) ranged from .61 to .74. In this study, the Cronbach's alpha coefficients for Perspective Taking, Empathic Concern and Personal Distress were .77, .70, and .77, respectively.

\section{Statistical Analysis}

All statistical tests were two-sided. T-tests, analysis of variance (ANOVA) and Bonferroni post hoc tests were used to contrast students' gender and academic year in FFMQ scores. Cohen's $d$ and eta-squared $\left(\eta^{2}\right)$ were calculated to estimate effect sizes for t-tests and ANOVA, respectively. A set of Pearson's correlations was performed to examine correlations between FFMQ facets, IRI dimensions, and age. Three hierarchical regression models explored the effects of FFMQ facets on each IRI dimension. For each regression model, gender, age, and academic year were introduced in Step 1 as covariate factors to control for their potential confounding effects. All the FFMQ subscale scores were added at Step 2. An increase in total IRI dimensions' variance explained at Step $2\left(\Delta R^{2}\right)$ would mean that the inclusion of the independent variables improved prediction of IRI scores. Bonferroni correction was applied and results were considered to be statistically significant at a $p$ value of $<$ .005. Standardized estimate $(\beta), F, R^{2}$ and $R^{2}$-changes $\left(\Delta R^{2}\right)$ for each step were provided. Incomplete questionnaires were excluded from the analyses. All analyses were performed using SPSS 24.0.

\section{Results}

\section{Sample Characteristics}

Out of the 722 students invited to take part to the study, 622 accepted and completed the questionnaire (response rate $=86.15 \%) .33 \%$ of students $(n=205)$ were enrolled in the first year, 33.4\% $(n=208)$ in the second year and 33.6\% $(n=209)$ were in their third year of studies. The majority 
$(82.2 \%, n=511)$ were female and had a mean age of 21.41 (standard deviation "SD" $=2.91$ ) years (range $=18-43)$. All students were Italian and with no children.

\section{Gender, Age, and Academic Year Differences in Dispositional Mindfulness and Empathy}

Levels of DM and empathy by gender and academic year are reported in Table 1. With regard to FFMQ subscales, females had higher levels of Acting with Awareness $[t(620)=-5.615, p<.001, d=.54]$ when compared with male students. Conversely, male students scored significantly higher than females on Non-reacting $[t(620)=5.303$, $p<.001, d=.52]$. Older students had higher scores on Observing ( $r=.112, p=.005)$ and Non-reacting ( $r=.187$, $p<.001)$ than younger ones. There were no statistically significant differences in DM levels between the three academic years $[F \mathrm{~s}(2619)<1.603, p s>.202]$. When it comes to the IRI dimensions, females had higher levels of Empathic
Concern $[t(620)=-6.404, p<.001, d=.64]$ and Personal Distress $[t(620)=-3.311, p=.001, d=.35]$ than males. No significant correlations were found between age and IRI subscales $[r s<.097, p s>.016]$. There were no statistically significant differences in empathy levels between the three academic years $[F \mathrm{~s}(2619)<1.519, p \mathrm{~s}>.220]$.

\section{Association between Dispositional Mindfulness Facets and Empathy Dimensions}

Correlations between DM facets and empathy dimensions are reported in Table 2 . Perspective Taking was positively related to Observing, Describing, Acting with Awareness, and Non-reacting. Empathic Concern was positively related to Observing, Describing, Acting with Awareness. On the other hand, Personal Distress was negatively correlated to Describing, Acting with Awareness, Non-judging, and Non-reacting. Statistically significant correlation coefficients
Table 1 Means and SD for the FFMQ and IRI subscales by gender and year of studies

\begin{tabular}{|c|c|c|c|c|c|}
\hline & \multicolumn{2}{|l|}{ Gender } & \multicolumn{3}{|c|}{ Academic year } \\
\hline & Male & Female & 1st year & 2nd year & 3rd year \\
\hline & $\mathrm{M}(\mathrm{SD})$ & $\mathrm{M}(\mathrm{SD})$ & $\mathrm{M}(\mathrm{SD})$ & $\mathrm{M}(\mathrm{SD})$ & $\mathrm{M}(\mathrm{SD})$ \\
\hline \multicolumn{6}{|l|}{ FFMQ } \\
\hline Observing & $25.75(5.40)$ & $25.74(6.02)$ & $25.20(6.05)$ & $25.81(5.94)$ & $26.20(5.74)$ \\
\hline Describing & $31.67(5.49)$ & $32.01(4.96)$ & $31.44(4.92)$ & $32.29(5.09)$ & $32.09(5.14)$ \\
\hline Acting with Awareness & $27.29(6.75)$ & $30.51(5.14)$ & $29.88(5.32)$ & $30.19(5.53)$ & $29.72(5.93)$ \\
\hline Non-judging & $26.39(6.14)$ & $27.23(5.72)$ & $26.77(5.89)$ & $27.12(5.79)$ & $27.33(5.74)$ \\
\hline Non-reacting & $20.76(4.67)$ & $18.54(3.84)$ & $18.69(4.06)$ & $18.80(4.00)$ & $19.31(4.18)$ \\
\hline \multicolumn{6}{|l|}{ IRI } \\
\hline Perspective Taking & 18.01(4.39) & $18.72(4.58)$ & $18.56(4.75)$ & $18.77(4.68)$ & $18.44(4.24)$ \\
\hline Empathic Concern & $17.59(4.62)$ & $20.38(4.07)$ & $19.56(4.24)$ & $20.28(4.54)$ & $19.80(4.10)$ \\
\hline Personal Distress & $8.34(4.25)$ & $9.83(4.31)$ & $9.18(4.45)$ & $9.69(4.49)$ & $9.82(4.04)$ \\
\hline
\end{tabular}

Table 2 Zero-order correlations between DM facets and empathy dimensions

\begin{tabular}{|c|c|c|c|c|c|c|c|c|}
\hline Variables & 1 & 2 & 3 & 4 & 5 & 6 & 7 & 8 \\
\hline 1. Observing & 1 & & & & & & & \\
\hline 2. Describing & $.269 * * *$ & 1 & & & & & & \\
\hline 3. Acting with Awareness & .008 & $.320 * * *$ & 1 & & & & & \\
\hline 4. Non-judging & $-.172 * * *$ & $.212 * * *$ & $.450 * * *$ & 1 & & & & \\
\hline 5. Non-reacting & $.205^{* * *}$ & $.271 * * *$ & .093 & $.138 * *$ & 1 & & & \\
\hline 6. Perspective Taking & $.234 * * *$ & $.255^{* * *}$ & $.180 * * *$ & .015 & $.265^{* * *}$ & 1 & & \\
\hline 7. Empathic Concern & $.209 * * *$ & $.216^{* * *}$ & $.142 * * *$ & -.019 & -.099 & $.413 * * *$ & 1 & \\
\hline 8. Personal Distress & -.049 & $-.251 * * *$ & $-.356^{* * * *}$ & $-.333 * * *$ & $-.260 * * *$ & -.077 & $.142 * * *$ & 1 \\
\hline $\mathrm{M}(\mathrm{SD})$ & $\begin{array}{l}25.74 \\
(5.91)\end{array}$ & $\begin{array}{l}31.95 \\
(5.06)\end{array}$ & $\begin{array}{l}29.93 \\
(5.59)\end{array}$ & $\begin{array}{l}27.08 \\
(5.80)\end{array}$ & $\begin{array}{l}18.93 \\
(4.08)\end{array}$ & $\begin{array}{l}18.59 \\
(4.55)\end{array}$ & $\begin{array}{l}19.88 \\
(4.30)\end{array}$ & $\begin{array}{l}9.57 \\
(4.33)\end{array}$ \\
\hline Range (min-Max) & $8-40$ & $8-40$ & $8-40$ & $8-40$ & $7-35$ & $0-28$ & $0-28$ & $0-28$ \\
\hline
\end{tabular}

$* * p<.005, * * * p<.001$ 
between FFMQ and IRI subscales ranged from $r=.142$ (weak association) to $r=-.356$ (moderate association).

Results of the hierarchical regressions exploring the effects of FFMQ facets on IRI dimensions are presented in Table 3. After controlling for gender, age, and year of study, Observing, Describing, Acting with Awareness, and Nonreacting were positively associated with Perspective Taking, accounting for $13.8 \%$ of its variance. After controlling for demographics, Observing and Describing were positively associated with Empathic Concern while Non-reacting was negatively associated with it, concurrently accounting for $8.9 \%$ of its variance. Acting with Awareness, Non-judging, and Non-reacting were negatively associated with Personal Distress and they collectively explained $21.8 \%$ of its variance beyond the effects of gender and age.

\section{Discussion}

Although many efforts have been made to assess the impact of mindfulness-based interventions on nursing professionals' and students' empathy, little attention has been paid to the association of DM and empathy in nursing students. We described DM and empathy in nursing students and investigated the association between these constructs carrying out the first study on the relationship between DM and empathy in this population. Our study highlighted that older nursing students are more able to observe and not to impulsively react to inner feelings than younger ones while a more scattered pattern of gender differences in DM emerged. No statistically significant differences in DM levels between the three academic years were found. Harboring our predictions, DM facets were generally positively related to the ability to embrace others' point of view and to feel compassion for people in need, whereas they were negatively related to a subjective feeling of discomfort in tense interpersonal situations.

\section{Dispositional Mindfulness by Gender, Age, and Academic Year}

Male nursing students, when compared with their female counterparts, had a higher dispositional ability to process emotions without reacting automatically to them. Nevertheless, female students showed to be more able to act with awareness than men. Our findings are only partially in line with previous studies showing that male students were more aware and nonreactive to their mental states than female students (Slonim et al., 2015). However, existing data have demonstrated that women score higher than males on some DM facets. Alispahic and Hasanbegovic-Anic (2017) have found that women, when compared to men, present a greater ability to observe and describe their thoughts. It has been advanced that females are less mindful than males because of their greater tendency to ruminate and to internalize thoughts (Tamres et al., 2002). The displaying of different emotion regulation strategies (Rojiani et al., 2017), levels of distress (Slonim et al., 2015), and cognitive functioning (Alispahic \& Hasanbegovic-Anic, 2017) between males and females have been also proposed to account for gender differences in dispositional mindfulness. Although the existing data on gender differences in DM is controversial and not conclusive, our results highlighted that gender differences in DM existed at baseline and should be thoroughly considered when tailoring interventions on specific mindfulness aspects.

Older students in our sample scored higher on Observing and Non-reacting facets. This result mirrors previous studies reporting a significant positive correlation between DM and age (Alispahic \& Hasanbegovic-Anic, 2017) and is in line with existing data showing that older people exhibit greater emotional control (Gross et al., 1997) and greater ability
Table 3 Hierarchical regressions exploring the effects of DM facets on empathy dimensions

\begin{tabular}{|c|c|c|c|c|c|c|}
\hline \multirow[t]{2}{*}{ Variables } & \multicolumn{2}{|c|}{ Perspective Taking } & \multicolumn{2}{|c|}{ Empathic Concern } & \multicolumn{2}{|c|}{ Personal Distress } \\
\hline & Step $1(\beta)$ & Step $2(\beta)$ & Step $1(\beta)$ & Step $2(\beta)$ & Step $1(\beta)$ & Step $2(\beta)$ \\
\hline Gender & .077 & .084 & $.262 * * *$ & $.211 * * *$ & $.116^{* *}$ & $.162 * * *$ \\
\hline Age & $.123 * *$ & .062 & .087 & .077 & -.111 & -.065 \\
\hline Academic year & -.053 & -.061 & -.009 & -.014 & .093 & .098 \\
\hline Observing & & $.138 * *$ & & $.171 * * *$ & & -.029 \\
\hline Describing & & $.131 * *$ & & $.189 * * *$ & & -.085 \\
\hline Acting with Awareness & & $.135^{* *}$ & & .071 & & $-.261 * * *$ \\
\hline Non-judging & & -.081 & & -.051 & & $-.193 * * *$ \\
\hline Non-reacting & & $.208 * * *$ & & $-.156 * * *$ & & $-.141 * * *$ \\
\hline $\mathrm{F}$ & 3.681 & $14.045 * * *$ & $15.424 * * *$ & $14.438 * * *$ & $6.876^{* * *}$ & $25.552 * * *$ \\
\hline $\mathrm{R}^{2}$ & .018 & .156 & .070 & .159 & .033 & .251 \\
\hline$\Delta \mathrm{R}^{2}$ & .018 & .138 & .070 & .089 & .033 & .218 \\
\hline
\end{tabular}

$* * p<.005, * * * p<.001$ 
to stay in the present moment (Mogilner et al., 2011). Age differences in DM have been linked to developmental interpretations which consider that as aging, individuals adapt and refine strategies of managing the intensity of their emotions, resolving in being less judging about themselves and others and being more able to focus in the present moment (Alispahic \& Hasanbegovic-Anic, 2017). This explanation is supported by Charles et al.' (2001) longitudinal scrutiny of four generations of families as older people showed to regulate their emotions more effectively than younger individuals and negative emotions decreased with age. Support to the developmental interpretations of age differences in DM is offered by the concept of Savouring which has been defined as the people's ability to "attend to, appreciate, and enhance the positive experiences in their lives" (Bryant et al., 2011) and which has been advanced to be linked to mindfulness (Sturgess, 2012). Older people showed greater tendency to savour the moment, to control emotions, to remain in the "here and now", and to be more mindful.

In line with our hypothesis on the role of academic seniority, no differences in DM have been found between students from the three academic years. Although it has been hypothesized that change in healthcare students' DM may occur without specific training as result of the emotional experiences of clinical training and of direct contact with patients (Ardenghi et al., 2021c), students involved in this study began clinical internship in their first year making not possible to appreciate the effect of clinical training on DM. We advise for future studies to include a baseline measure of DM before clinical internship to test this hypothesis.

\section{Association between Dispositional Mindfulness and Empathy}

In our sample most DM facets were negatively correlated to difficulties in managing distress and worries in tense interpersonal settings (Personal Distress), while they were positively related to the ability to feel concern for unfortunate others (Empathic Concern) and spontaneously adopt other people's perspective (Perspective Taking). Our results are in line with our hypothesis and with the existing literature (Thomas et al., 2007) suggesting that DM helps individuals to lessen the subjective level of emotional distress and to be more receptive towards others' needs and feelings. Yet, it has to be noted that literature on the association between DM facets and empathy dimensions is not clear-cut offering inconsistent and heterogeneous correlation patterns (Beitel et al., 2005; Berry et al., 2018; Dekeyser et al., 2008). Although a direct comparison of our findings with existing investigations could be hindered by differences in instruments and methods used and by the scarcity of data, a general agreement on the association between DM facets and Perspective Taking and Empathic Concern emerged, while a more scattered picture resulted from the comparison between our findings and the literature on the association between DM and Personal Distress. To better read how our results contribute to the literature, we need to discuss how the different empathy dimensions relate to DM facets.

When focusing on each IRI subscale, Perspective Taking in our sample was associated with four out of the five facets of DM. Previous studies (Block-Lerner et al., 2007) highlighted the role of DM facets in cultivating openness and interest in others' experiences result is also consistent with existing evidence (Beitel et al., 2005; Berry et al., 2018) showing that paying attention to inner states and acting with awareness were positively associated with Perspective Taking supporting the theoretical hypothesis that DM contributes to the awareness of others' needs. The nursing students' ability to act with awareness, observe and describe their emotions, and prevent automatic emotionally-charged reactions could equip them to better understand other people's feelings and to consider their perspective.

Empathic Concern was positively related to Observing and Describing facets of DM and negatively correlated with Non-reacting. Using different tools to assess DM, other studies (Beitel et al., 2005; Berry et al., 2018) highlighted a positive association between Empathic Concern and the ability to be aware of and pay attention to one's own inner states. A study on married couples (Wachs \& Cordova, 2007) also reported significant correlations between DM and Empathic Concern. The negative association between Empathic Concern and Non-reacting in our sample mirrors MacDonald and Price's findings (2017). As Empathic Concern measures the tendency to feel sympathy and concern for the misfortune of others, it is not surprising that nursing students who tend to detach themselves from their negative thoughts and emotions (and control their automatic emotionally-charged reactions) are less inclined to have feelings of preoccupation for others.

Finally, we found that Personal Distress in demanding interpersonal settings was associated to lower levels of DM. This result mirrors Dekeyser et al.' (2008) negative relationship between several DM facets (Awareness, Acceptance, and Describing) and Personal Distress, as well as Beitel and colleagues' results (2005) reporting a negative correlation between Personal Distress and both the ability to pay attention and the ability to be aware. Our results also align with findings from a sample of Australian undergraduate medical students where lower levels of depressive, anxiety, and stress symptoms were associated with higher levels of DM facets except the Observing subscale (Slonim et al., 2015). Our study adds evidence to the beneficial and protective role of DM on emotional distress in tense situations supporting the account that DM disentangles the level to which distress is experienced in response to aversive internal and external events (Feldman et al., 2016). In contrast to our results and 
the abovementioned studies, however, Berry et al. (2018) reported a non-significant correlation between the Acting with Awareness subscale of the FFMQ and the Personal Distress dimension of the IRI and a positive association between Personal Distress and the total score of the Mindful Attention Awareness Scale (MAAS; Brown \& Ryan, 2003). Being the total score of the MAAS a non-faceted measure of DM, it is difficult to tackle which DM aspects are responsible for the positive association with Personal Distress, thus impairing a direct comparison with our more faceted findings.

\section{Strengths and Limitations}

The use of internationally validated and reliable measures that have been widely used in nursing education research allows cross-national comparisons strengthening the study conclusions. Nevertheless, as we used self-reported measurements and focused on the nursing student population, our results should be generalized with caution. The crosssectional design of the study poses a methodological limit to the inferential power of our scrutiny as it provides a snapshot at one time-point preventing to establish the direction of the relationship between DM and empathy. Furthermore, we missed to assess students' previous and current experience with meditation and mindfulness-based activities.

\section{Conclusion}

The findings of this study support the association between DM and the emotional and cognitive components of empathy in undergraduate nursing students. We found that nursing students with higher levels of DM were more able to consider others' cognitive perspective and to feel compassion, and were less emotionally distressed when facing tense interpersonal situations. Our findings suggest that mindfulness programs may be tailored to cultivate specific DM facets and could be integrated in nursing curricula. As we controlled for gender, age, and year of study effects, we advance that these programs could be implemented at all stages of the nursing academic path. These programs have the potential to nurture students' cognitive capability to consider other individuals' perspectives, to promote compassion for others, and to reduce emotional distress in demanding interpersonal settings.

Author Contributions Conceptualization: Stefano Ardenghi, Stefania Di Mauro, Maria Grazia Strepparava; Data curation: Stefano Ardenghi, Valerio Salvarani; Formal Analysis: Stefano Ardenghi; Investigation: Valerio Salvarani, Giulia Rampoldi; Methodology: Stefano Ardenghi, Michela Luciani, Valerio Salvarani, Giulia Rampoldi, Marco Bani, Davide Ausili; Visualization: Stefano Ardenghi, Michela Luciani; Writing - original draft: Stefano Ardenghi, Selena Russo, Michela Luciani,
Davide Ausili; Writing - review \& editing: Stefano Ardenghi, Selena Russo, Michela Luciani, Valerio Salvarani, Giulia Rampoldi, Marco Bani, Davide Ausili, Stefania Di Mauro, Maria Grazia Strepparava; Project administration: Stefania Di Mauro, Maria Grazia Strepparava; Supervision: Stefania Di Mauro, Maria Grazia Strepparava.

Data Availability The datasets generated during and/or analyzed during the current study are available from the corresponding author on reasonable request.

\section{Declarations}

Conflicts of Interest/Competing Interests The authors have no relevant financial or non-financial interests to disclose.

Open Access This article is licensed under a Creative Commons Attribution 4.0 International License, which permits use, sharing, adaptation, distribution and reproduction in any medium or format, as long as you give appropriate credit to the original author(s) and the source, provide a link to the Creative Commons licence, and indicate if changes were made. The images or other third party material in this article are included in the article's Creative Commons licence, unless indicated otherwise in a credit line to the material. If material is not included in the article's Creative Commons licence and your intended use is not permitted by statutory regulation or exceeds the permitted use, you will need to obtain permission directly from the copyright holder. To view a copy of this licence, visit http://creativecommons.org/licenses/by/4.0/.

\section{References}

Albiero, P., Ingoglia, S., \& Lo Coco, A. (2006). Contributo all' adattamento italiano dell'Interpersonal Reactivity Index. TPM - Testing Psicometria Metodologia, 13(2), 107-125.

Alispahi, S., \& Hasanbegovi-Anic, E. (2017). Mindfulness: Age and gender differences on a Bosnian sample. Psychological Thought, $10,155-166$.

Ardenghi, S., Luciani, M., Rampoldi, G., Ausili, D., Bani, M., Di Mauro, S., \& Strepparava, M. G. (2021a). Personal values among first-year medical and nursing students: A cross-sectional comparative study. Nurse Education Today, 100, 104827. https://doi. org/10.1016/j.nedt.2021.104827

Ardenghi, S., Rampoldi, G., Bani, M., \& Strepparava, M. G. (2020a). Attachment styles as predictors of self-reported empathy in medical students during pre-clinical years. Patient Education and Counseling, 103(5), 965-970. https://doi.org/10.1016/j.pec. 2019.11.004

Ardenghi, S., Rampoldi, G., Bani, M., \& Strepparava, M. G. (2021b). Personal values as early predictors of emotional and cognitive empathy among medical students. Current Psychology. https:// doi.org/10.1007/s12144-021-01373-8

Ardenghi, S., Rampoldi, G., Pepe, A., Bani, M., Gritti, P., \& Strepparava, M. G. (2020b). Assessing patient-centeredness among medical students: The Italian translation and validation of the patient-practitioner orientation scale. BPA-applied psychology bulletin (Bollettino di Psicologia Applicata), LXVII, 285, 51-61. https://doi.org/10.26387/bpa.285.5.

Ardenghi, S., Rampoldi, G., Pepe, A., Bani, M., Salvarani, V., \& Strepparava, M. G. (2021c). An exploratory Cross-sectional study on the relationship between dispositional mindfulness and empathy in undergraduate medical students. Teaching and Learning in Medicine, 33(2), 154-163. https://doi.org/10.1080/10401334. 2020.1813582 
Ardenghi, S., Russo, S., Bani, M., Rampoldi, G., \& Strepparava, M. G. (2021d). The role of difficulties in emotion regulation in predicting empathy and patient-centeredness in pre-clinical medical students: A cross-sectional study. Psychology, Health \& Medicine, 1-15. https://doi.org/10.1080/13548506.2021.2001549

Baer, R. A., Smith, G. T., Hopkins, J., Krietemeyer, J., \& Toney, L. (2006). Using self-report assessment methods to explore facets of mindfulness. Assessment, 13(1), 27-45. https://doi.org/10.1177/ 1073191105283504

Baillie, L. (1996). A phenomenological study of the nature of empathy. Journal of Advanced Nursing, 24(6), 1300-1308.

Barbaranelli, C., Ghezzi, V., Ardenghi, S., Caiaffa, M. F., Muraro, R., Cavaggioni, G., Valli, M., Piga, A., Di Liegro, I., Strepparava, M. G., \& Familiari, G. (2021). The contribution of personality traits and self-efficacy beliefs to medical students' empathy. Testing, Psychometrics, Methodology in Applied Psychology, 28, 313-327. https://doi.org/10.4473/ TPM28.3.3

Beddoe, A. E., \& Murphy, S. O. (2004). Does mindfulness decrease stress and foster empathy among nursing students? The Journal of Nursing Education, 43(7), 305-312.

Beitel, M., Ferrer, E., \& Cecero, J. J. (2005). Psychological mindedness and awareness of self and others. Journal of Clinical Psychology, 61(6), 739-750. https://doi.org/10.1002/jclp.20095

Berry, D. R., Cairo, A. H., Goodman, R. J., Quaglia, J. T., Green, J. D., \& Brown, K. W. (2018). Mindfulness increases prosocial responses toward ostracized strangers through empathic concern. Journal of Experimental Psychology. General, 147(1), 93-112. https://doi.org/10.1037/xge0000392

Block-Lerner, J., Adair, C., Plumb, J. C., Rhatigan, D. L., \& Orsillo, S. M. (2007). The case for mindfulness-based approaches in the cultivation of empathy: Does nonjudgmental, present-moment awareness increase capacity for perspective-taking and empathic concern? [article]. Journal of Marital and Family Therapy, 33(4), 501-516. https://doi.org/10.1111/j.1752-0606.2007.00034.x

Brown, K. W., \& Ryan, R. M. (2003). The benefits of being present: Mindfulness and its role in psychological well-being. Journal of Personality and Social Psychology, 84(4), 822-848. https://doi. org/10.1037/0022-3514.84.4.822

Brunero, S., Lamont, S., \& Coates, M. (2010). A review of empathy education in nursing. Nursing Inquiry, 17(1), 65-74. https://doi. org/10.1111/j.1440-1800.2009.00482.x

Bryant, F. B., Chadwick, E. D., \& Kluwe, K. (2011). Understanding the processes that regulate positive emotional experience: Unsolved problems and future directions for theory and research on savoring. International Journal of Wellbeing, 1(1), 107-126. https:// doi.org/10.5502/ijw.v1i1.18

Chamberlain, D., Williams, A., Stanley, D., Mellor, P., Cross, W., \& Siegloff, L. (2016). Dispositional mindfulness and employment status as predictors of resilience in third year nursing students: A quantitative study. Nursing Open, 3(4), 212-221. https://doi.org/ 10.1002/nop2.56

Charles, S. T., Reynolds, C. A., \& Gatz, M. (2001). Age-related differences and change in positive and negative affect over 23 years. Journal of Personality and Social Psychology, 80(1), 136-151. https://doi.org/10.1037/0022-3514.80.1.136

Davis, M. H. (1980). A multidimensional approach to individual differences in empathy. JSAS Catalog of Selected Documents in Psychology, 10, 85.

de Bruin, E. I., Meppelink, R., \& Bögels, S. M. (2015). Mindfulness in higher education: Awareness and attention in university students increase during and after participation in a mindfulness curriculum course. Mindfulness, 6(5), 1137-1142. https://doi.org/10. 1007/s12671-014-0364-5

Dekeyser, M., Raes, F., Leijssen, M., Leysen, S., \& Dewulf, D. (2008). Mindfulness skills and interpersonal behaviour [article].
Personality and Individual Differences, 44(5), 1235-1245. https:// doi.org/10.1016/j.paid.2007.11.018

Derksen, F., Olde Hartman, T. C., van Dijk, A., Plouvier, A., Bensing, J., \& Lagro-Janssen, A. (2017). Consequences of the presence and absence of empathy during consultations in primary care: A focus group study with patients. Patient Education and Counseling, 100(5), 987-993. https://doi.org/10.1016/j.pec.2016.12.003

Donald, J. N., Sahdra, B. K., Van Zanden, B., Duineveld, J. J., Atkins, P. W. B., Marshall, S. L., \& Ciarrochi, J. (2019). Does your mindfulness benefit others? A systematic review and meta-analysis of the link between mindfulness and prosocial behaviour. British Journal of Psychology, 110(1), 101-125. https://doi.org/10.1111/ bjop. 12338

Doyle, K., Hungerford, C., \& Cruickshank, M. (2014). Reviewing tribunal cases and nurse behaviour: Putting empathy back into nurse education with Bloom's taxonomy. Nurse Education Today, 34(7), 1069-1073. https://doi.org/10.1016/j.nedt.2014.02.004

Duncan, L. G., \& Bardacke, N. (2010). Mindfulness-based childbirth and parenting education: Promoting family mindfulness during the perinatal period. Journal of Child and Family Studies, 19(2), 190-202. https://doi.org/10.1007/s10826-009-9313-7

Feldman, G., Lavalle, J., Gildawie, K., \& Greeson, J. M. (2016). Dispositional mindfulness uncouples physiological and emotional reactivity to a laboratory stressor and emotional reactivity to executive functioning lapses in daily life. Mindfulness, 7(2), 527-541. https://doi.org/10.1007/s12671-015-0487-3

Fragkos, K. C., Sotiropoulos, I., \& Frangos, C. C. (2019). Empathy assessment in healthcare students is highly heterogeneous: A systematic review and meta-analysis (2012-2016). World Journal of Meta-Analysis, 7(1), 1-30. https://doi.org/10.13105/wjma.v7.i1.1

Fuochi, G., \& Voci, A. (2020). A deeper look at the relationship between dispositional mindfulness and empathy: Meditation experience as a moderator and dereification processes as mediators. Personality and Individual Differences, 165, 110122. https://doi. org/10.1016/j.paid.2020.110122

Giovannini, C., Giromini, L., Bonalume, L., Tagini, A., Lang, M., \& Amadei, G. (2014). The Italian five facet mindfulness questionnaire: A contribution to its validity and reliability. Journal of Psychopathology and Behavioral Assessment, 36(3), 415-423. https:// doi.org/10.1007/s10862-013-9403-0

Gross, J. J., Carstensen, L. L., Pasupathi, M., Tsai, J., Skorpen, C. G., \& Hsu, A. Y. C. (1997). Emotion and aging: Experience, expression, and control. Psychology and Aging, 12(4), 590-599. https://doi. org/10.1037/0882-7974.12.4.590

Hegel, J., Halkett, G. K. B., Schofield, P., Rees, C. S., Heritage, B., Suleman, S., Inhestern, L., Butler, T., Fitch, M. I., \& Breen, L. J. (2021). The relationship between present-Centered awareness and attention, burnout, and compassion fatigue in oncology health professionals. Mindfulness, 12(5), 1224-1233. https://doi.org/10. 1007/s12671-020-01591-4

Hojat, M., Mangione, S., Kane, G. C., \& Gonnella, J. S. (2005). Relationships between scores of the Jefferson scale of physician empathy (JSPE) and the interpersonal reactivity index (IRI). Medical Teacher, 27(7), 625-628. https://doi.org/10.1080/0142159050 0069744

Jinpa, T., Rosenberg, E., McGonigal, K., Cullen, M., Goldin, P., \& Ramel, W. (2009). Compassion cultivation training (CCT): An eight-week course on cultivating compassionate heart and mind. Unpublished manuscript, Center for Compassion and Altruism Research and Education, Stanford University, Stanford, CA.

Kabat-Zinn, J. (2003). Mindfulness-based interventions in context: Past, present, and future. Clinical Psychology: Science and Practice, 10(2), 144-156. https://doi.org/10.1093/clipsy.bpg016

Luciani, M., Rampoldi, G., Ardenghi, S., Bani, M., Merati, S., Ausili, D., Strepparava, M. G., \& Di Mauro, S. (2020). Personal values among undergraduate nursing students: A cross-sectional study. 
Nursing Ethics, 27(6), 1461-1471. https://doi.org/10.1177/09697 33020914350

MacDonald, H. Z., \& Price, J. L. (2017). Emotional understanding: Examining alexithymia as a mediator of the relationship between mindfulness and empathy. Mindfulness, 8(6), 1644-1652. https:// doi.org/10.1007/s12671-017-0739-5

Mogilner, C., Kamvar, S. D., \& Aaker, J. (2011). The shifting meaning of happiness. Social Psychological and Personality Science, 2(4), 395-402. https://doi.org/10.1177/1948550610393987

Ozcan, C., Oflaz, F., \& Sutcu Cicek, H. (2010). Empathy: The effects of undergraduate nursing education in Turkey. International Nursing Review, 57(4), 493-499.

Richardson, K., MacLeod, R., \& Kent, B. (2012). A Steinian approach to an empathic understanding of hope among patients and clinicians in the culture of palliative care. Journal of Advanced Nursing, 68(3), 686-694. https://doi.org/10.1111/j.1365-2648.2011. 05793.x

Rojiani, R., Santoyo, J. F., Rahrig, H., Roth, H. D., \& Britton, W. B. (2017). Women benefit more than men in response to collegebased meditation training. Frontiers in Psychology, 8, 551. https:// doi.org/10.3389/fpsyg.2017.00551

Salvarani, V., Ardenghi, S., Rampoldi, G., Bani, M., Cannata, P., Ausili, D., Di Mauro, S., \& Strepparava, M. G. (2020). Predictors of psychological distress amongst nursing students: A multicenter cross-sectional study. Nurse Education in Practice, 44, 102758. https://doi.org/10.1016/j.nepr.2020.102758

Salvarani, V., Rampoldi, G., Ardenghi, S., Bani, M., Blasi, P., Ausili, D., Di Mauro, S., \& Strepparava, M. G. (2019). Protecting emergency room nurses from burnout: The role of dispositional mindfulness, emotion regulation and empathy. Journal of Nursing Management, 27(4), 765-774. https://doi.org/10.1111/jonm. 12771

Shamay-Tsoory, S. G. (2011). The neural bases for empathy. Neuroscientist, 17(1), 18-24. https://doi.org/10.1177/1073858410379268

Slonim, J., Kienhuis, M., Di Benedetto, M., \& Reece, J. (2015). The relationships among self-care, dispositional mindfulness, and psychological distress in medical students. Medical Education Online, 20(13), 27924. https://doi.org/10.3402/meo.v20.27924
Sturgess, M. (2012). Psychometric validation and demographic differences in two recently developed trait mindfulness measures Victoria University of Wellington]. http://researcharchive.vuw. ac.nz/handle/10063/2569?show=full

Tamres, L. K., Janicki, D., \& Helgeson, V. S. (2002). Sex differences in coping behavior: A Meta-analytic review and an examination of relative coping. Personality and Social Psychology Review, 6(1), 2-30. https://doi.org/10.1207/s15327957pspr0601_1

Thomas, M. R., Dyrbye, L. N., Huntington, J. L., Lawson, K. L., Novotny, P. J., Sloan, J. A., \& Shanafelt, T. D. (2007). How do distress and well-being relate to medical student empathy? A multicenter study. Journal of General Internal Medicine, 22(2), 177-183. https://doi.org/10.1007/s11606-006-0039-6

Voci, A., Veneziani, C. A., \& Bernardi, S. (2016). Dispositional mindfulness and self-compassion as predictors of work-related wellbeing. Psicologia Sociale, 11(1), 69-88.

Wachs, K., \& Cordova, J. V. (2007). Mindful relating: Exploring mindfulness and emotion repertoires in intimate relationships [article]. Journal of Marital and Family Therapy, 33(4), 464-481. https:// doi.org/10.1111/j.1752-0606.2007.00032.x

Wallmark, E., Safarzadeh, K., Daukantaitè, D., \& Maddux, R. E. (2013). Promoting altruism through meditation: An 8-week randomized controlled pilot study. Mindfulness, 4(3), 223-234. https:// doi.org/10.1007/s12671-012-0115-4

Wilczek-Rużyczka, E. (2011). Empathy vs. professional burnout in health care professionals. Journal of US-China Medical Science, $8(9), 526-532$.

Yang, S., Meredith, P., \& Khan, A. (2017). Is mindfulness associated with stress and burnout among mental health professionals in Singapore? Psychology, Health \& Medicine, 22(6), 673-679. https:// doi.org/10.1080/13548506.2016.1220595

Publisher's Note Springer Nature remains neutral with regard to jurisdictional claims in published maps and institutional affiliations. 